\title{
Correspondence
}

\section{Self-help for taxonomists: three things we must do for taxonomy to survive}

\author{
GEOFF A. BOXSHALL \\ Department of Life Sciences, Natural History Museum, Cromwell Road, London SW7 5BD, United Kingdom: $\equiv "$ g.boxshall@nhm.ac.uk; \\ (1) https://orcid.org/0000-0001-8170-7734
}

In the mid Nineteenth Century taxonomy was at the cutting edge of zoology but there were periods in the later Twentieth Century where it seems to me that it was viewed as a quaint folk industry. With the resurgence of natural history and the focus on biodiversity change, the current perception lies somewhere between these two extremes, but taxonomists need to be able to articulate the importance of what they do in terms of its relevance to society. The role of the taxonomist has six main strands: 1) determining identity (diagnostics), 2) establishing and revising taxa, 3) building phylogenetic systems, 4) integrating biological information to build "species biographies", 5) creating identification tools, and 6) training the next generation of taxonomists. Given that there is no such entity as a typical taxonomist, the relative priority of these strands will vary from individual to individual, but all professional taxonomists should be able to place their work in its appropriate higher level context, be it human health, the sustainable provision of ecosystem services, biodiversity conservation, etc.

Taxonomy was considered under threat in the UK (House of Lords' Select Committee on Science and Technology, 2008) and was identified as a critical skills gap in a review of skills requirements in the environmental sector over the decade ending in 2020 (ERFF, 2010). These skills were recognized as crucial for "monitoring and understanding the functionality of the marine environments", and for "recognising the role of biodiversity and ecosystem resilience in a changing climate". The critical shortage of taxonomic skills was also apparent in other highlighted areas, including fieldworkwhere "survey skills including species identification" was a specific need, and Sustainability Science and Planningwhere "environmental impact assessment" was a specific need. Knapp \& Boxshall (2010) concluded that "at the very time when the importance of biodiversity has been realised, our capability of describing and documenting it has been eroded to a crisis point." It seems to me that little has changed since then but other contributions are focusing on the overall problem so I want to use this article to highlight three practical challenges for taxonomy going forwards.

\section{Maintaining and enhancing the system of Reciprocal Illumination}

Molecular sequencing technology has been a huge boost to diagnostics. I remember back in the late 1970s when a taxonomist colleague was called as an expert witness at a murder trial to give evidence on the identity of the amphipods found in the clothing of a body washed ashore in a UK estuary. He had written the book on amphipod identification and his testimony was not challenged, but can you imagine turning up in court today to give testimony without the back-up of molecular data? Sequencing is an essential tool for taxonomy but diagnostics is often only a small part of a taxonomist's role and the idea that taxonomists can be replaced by sequencers is wrong.

Reciprocal illumination between morphological systematics and molecular sequence-based systematics lies at the heart of modern integrated taxonomy. The challenge provided by early molecular-based phylogenetic studies has entirely reshaped views of relationships between animal phyla (e.g. Aguinaldo et al., 1997) and stimulated morphologists to revisit their data in order to understand the newly revealed evolutionary patterns. At the level of phyla this process of challenge has been effective in providing reciprocal illumination at least in part because the morphological-trait and molecularsequence data sets were equally comprehensive and similar in granularity. At the species level however, the process of challenge has more often resulted in shock and awe, with molecular data revealing unimagined levels of cryptic speciation. For example, many familiar European polychaete worm species are now considered to represent clusters of species that cannot or can barely be separated morphologically (e.g. Nygren et al., 2018). In such cases, where genetic divergence and morphological divergence are "out of sync", the concept of reciprocal illumination is not applicable and the methodological approach will be dictated by the objectives of the study.

At more intermediate levels in the taxonomic hierarchy, there is often a mismatch between morphological and molecular data sets in terms of granularity. This mismatch stems from the difference in 
time required to generate the data. The recent analysis by Khodami et al. (2019) of relationships within the order Cyclopoida (Crustacea: Copepoda) serves as an example. This extensive molecular analysis recovered four major groupings within the order and four new suborders were proposed which have already been widely adopted (e.g. Walter \& Boxshall, 2019). It included sequence data from 181 in-group taxa of which $92(50.8 \%)$ were identified to species, $73(40 \%)$ identified to genus, $11(6.1 \%)$ to family and $3(1.7 \%)$ to order. However, if we consider the level of identification as a surrogate for the level of available morphological detail, then there is a mismatch in the level of granularity since the morphology of $49.2 \%$ of the taxa has not yet been fully elucidated. Given that much of the incompletely identified material in Khodami et al. (2019) is likely new to science, this mismatch is understandable as it takes time to work up the descriptions. However, for the duration of the time lag any reciprocal illumination breaks down as our morphological knowledge is failing to keep up. As an example here, I refer to a small copepod clade recovered by Khodami et al. (2019) comprising the Archinotodelphyidae and Notodelphyidae, both of which contain symbionts of tunicates. These symbiotic families lie within a larger, mostly free-living clade including the marine benthic Cyclopinidae, the planktonic Oithonidae, plus a third family ("Cyclopoida sp."). This unknown family (collected from the enormous depth of $9540 \mathrm{~m}$ in the North Pacific) is recovered as the sister taxon of the Archinotodelphyidae + Notodelphyidae in Khodami et al.'s scheme, so until its morphology is revealed we will remain unable to explore the morphological impact of the major change in mode of life from free-living to symbiotic within the wider clade.

Whilst molecular sequence-driven phylogenetics has its problems, for example with inadequate and inequitable taxon sampling across taxa (Brothers, 2019), it is clear that we need to put more effort into morphological systematics in order to maximise the value of phylogenetics. This is no trivial challenge but is essential if we are to maintain the value of phylogenies as tools for predicting the biological properties of unknown or poorly-known taxa.

\section{Building and maintaining taxonomic information systems}

Modern taxonomy is conducted in an increasingly connected world and this connectivity provides ready access to immensely valuable resources for taxonomists. From our desks we can access great swathes of older taxonomic literature via the Biodiversity Heritage Library, as well as distribution data (e.g. Global Biodiversity Information Facility), molecular data (e.g. GenBank), and phylogenetic trees (e.g. Tree of Life Web Project).
Species names (the formal Linnaean binomials) provide an index to the content of these on-line databases, so comprehensive registers of valid names are vital. In the marine world we are fortunate to have the open-access World Register of Marine Species (WoRMS) which began as a resource covering marine taxa but is now expanding to include all aquatic taxa and even some terrestrial groups (www.marinespecies.org). WoRMS aims to provide an authoritative and comprehensive list of names of all marine organisms, including information on synonymy. The taxonomic content of WoRMS is controlled by taxonomists, not by database managers, and each taxonomic group is represented by one or more experts who have authority over the content and are responsible for quality control. For certain taxa the taxonomic data served by WoRMS come from externally hosted global species databases, such as AlgaeBase (www.algaebase. org) and FishBase (www.Fishbase.org).

Maintaining WoRMS depends upon the commitment of over 200 expert taxonomists from around the world who scan the literature to capture and enter new taxa and new literature, and update content where necessary. While some of this basic data capture will eventually become automated, the taxonomic editors will remain responsible for quality control and validation. For my own research, I used to maintain my own working index of valid copepod names and synonyms. Now such records are updated on WoRMS, which has the huge advantage that the entire copepod research community has access to the same set of names. The community-based process for generating such species databases also provides a robust and relatively stable nomenclature.

The challenge here is to find new expert editors (to replace those retiring) from an apparently shrinking global pool of professional taxonomists. Many institutions see such a role as providing a service but not as research and it can be difficult for younger taxonomists to get approval of formal job descriptions that include contributing to databases. In order to attract the next generation of editors we need to better articulate the importance of taxonomic databases to a diverse array of users, and to develop a better system to reward and recognise the expert contributions of the editors. A complementary approach should be to widen the net to engage with the non-professional taxonomists who do taxonomy on an unpaid voluntary basis. Fontaine et al. (2012) analysed the authorship of the 5,881 new species described during the decade 1998 to 2007 from European terrestrial and freshwater habitats (as recorded in Fauna Europaea, www.faunaeur.org) and found that volunteers described $62.2 \%$ of the new species, including $52.7 \%$ of the new flies (Diptera) and $26.7 \%$ of the mites (Acari). This highly productive volunteer sector is increasingly important and should be much better integrated into the global taxonomic community. 


\section{Addressing issues of societal relevance}

Most taxonomic institutions are funded by public money, so it is incumbent on them to demonstrate the societal relevance of their work. Issues such as wealth generation and human health have long been high on governments' agendas, but emerging issues such as managing the impact of climate change and environmental health are rapidly climbing the priority list. Governments also have to meet their obligations under international conventions, such as the Convention on Biological Diversity. All such drivers of public spending help us frame the funding context within which taxonomy must compete to survive. Most taxonomists maintain a portfolio of research interests and, as a specialist on copepods, I always needed to ensure that mine included some projects that were of obvious societal relevance, as well as some where I had to work harder to explain their importance. The general area of opportunity I want to highlight here is parasite taxonomy. Taxonomic effort has never been evenly spread across the animal kingdom and one area of particular neglect is symbionts in general and parasites in particular.

Our knowledge of marine parasites appears fragmentary and one of the causes of this, especially in the case of invertebrate hosts, is low prevalence rates. The recent discovery of multiple new parasitic taxa on polychaete hosts in European waters (Kim et al., 2013; Boxshall et al., 2015, 2019) can be attributed, at least in part, to the large numbers of potential hosts screened during the numerous macrobenthos surveys that provided the material. These parasites are assumed to be rare and have therefore eluded detection even in the relatively well studied European fauna. However, despite low prevalence rates, the very large sample sizes revealed a remarkable level of novelty, viz. two new families, ten new genera and 26 new species. Despite the intrinsic interest of new taxa, research on parasites of marine invertebrates has always been harder to "sell" than research on parasites of fishes.

The parasites and symbionts of marine vertebrate hosts are generally better known than those of invertebrate hosts, although estimates of species richness of metazoan parasites in coral reef fishes suggest that current knowledge of fish parasite diversity is still very incomplete. Justine et al. (2010a, b, 2012) surveyed the metazoan parasite biodiversity for fourmajor families ofreef-associated fishes (Lutjanidae, Nemipteridae, Serranidae and Lethrinidae) in New Caledonia, concluding that well-sampled fish have a mean of 20 host-parasite combinations per fish species, and that the number of parasites identified at the species level is 10 per fish species. They also suggested that it is likely that only $3 \%$ of the parasite species of coral reef fish are already known in New Caledonia and this level of sampling impairs proper biogeographical or ecological comparisons.

The challenge of improving our knowledge base of parasite species, especially parasites of hosts that have commercial potential, has direct societal relevance. For example, more and more finfish species are being taken into commercial aquaculture. Globally, when any marine finfish is brought into culture for the first time, problems due to infection by parasites such as sea lice (Copepoda: Caligidae) emerge within two or three years, sometimes within months. Correct identification of the parasites and pathogens involved is essential if the infection is to be managed successfully. Highlighting the economic importance of accurate diagnostics, whether focused on parasites, on pollinators, or on invasive species, is only part of the overall justification for taxonomy but it is the part most likely to be heard.

Taxonomy is not carried out in isolation and taxonomists need to engage with its funders and its many different users in order to secure its future. Research communities in taxonomy are typically taxon-based, so we have many, but all need to be welcoming to new entrants. Above all we need to communicate the excitement of taxonomy as well as its worthiness, in order to attract new recruits to enter the field.

\section{References}

Aguinaldo, A.M.A., Turbeville, J.M., Linford, L.S., Rivera, M.C., Garey, J.R., Raff, R.A. \& Lake, J.A. (1997) Evidence for a clade of nematodes, arthropods, and other moulting animals. Nature, 387 (6632), 489-493. https://doi.org/10.1038/387489a0

Boxshall, G.A., O'Reilly, M., Sikorski, A. \& Summerfield, R. (2015) A new genus and family of copepods (Crustacea: Copepoda) parasitic on polychaetes of the genus Jasmineira Langerhans, 1880 (family Sabellidae) in the northeastern Atlantic. Zootaxa, 4018 (3), 426-436. https://doi.org/10.11646/zootaxa.4018.3.6

Boxshall, G.A., O'Reilly, M., Sikorski, A. \& Summerfield, R. (2019) Mesoparasitic copepods (Copepoda: Cyclopoida) associated with polychaete worms in European seas. Zootaxa, 4579 (1), 1-69. https://doi.org/10.11646/zootaxa.4579.1.1

Brothers, D.J. (2019) Aculeate Hymenoptera: Phylogeny and Classification. In: Starr, C. (Ed.), Encyclopedia of Social Insects. Springer Nature, Switzerland, pp. 1-9. https://doi.org/10.1007/978-3-319-90306-4 1-1

ERFF [Environmental Research Funders' Forum]. (2010) Most Wanted. Skills Needs in the Environmental Sector. ERFF Report07.[http://www.ukcds.org.uk/_assets/file/publications/ ERFF-Most-Wanted-report.pdf]

Fontaine, B., Van Achterberg, K., Alonso-Zarazaga, M.A., Araujo, R., Asache, M., Aspöck, H., Aspöck, U., Audisio, P., Aukema, B., Bailly, N., Balsamo, M., Bank, R.A., Belfiore, C., Bogdanowicz, W., Boxshall, G.A., Burckhardt, D., Chylarecki, 
P., Deharveng, L., Dubois, A., Enghoff, H., Fochetti, R., Fontaine, C., Gargominy, O., Gomez Lopez, M.S., Goujet, D., Harvey, M.S., Heller, K.-G., Van Helsdingen, P., Hoch, H., De Jong, Y., Karsholt, O., Los, W., Magowski, W., Massard, J.A., McInnes, S.J., Mendes, L.F., Mey, E., Michelsen, V., Minelli, A., Nieto Nafrýa, J.M., Van Nieukerken, E.J., Pape, T., De Prins, W., Ramos, M., Ricci, C., Roselaar, C., Rota, E., Segers, H., Timm, T., Van Tol, J. \& Bouchet, P. (2012) New Species in the Old World: Europe as a Frontier in Biodiversity Exploration, a Test Bed for 21st Century Taxonomy. PLoS ONE, 7 (5), e36881.

https://doi.org/10.1371/journal.pone.0036881

House of Lords' Select Committee on Science and Technology. (2008) Systematics and Taxonomy Followup: Report with Evidence. 5th report (2007-08) (HL Paper 162). The Stationery Office Limited, London.

Humes, A.G. (1994) How many copepods? Hydrobiologia, 292/293, 1-7.

Justine, J.-L., Beveridge, I., Boxshall, G.A., Bray, R.A., Moravec, F., Trilles, J.-P. \& Whittington, I.D. (2010a) An annotated list of parasites (Isopoda, Copepoda, Monogenea, Digenea, Cestoda and Nematoda) collected in groupers (Serranidae, Epinephelinae) in New Caledonia emphasizes parasite biodiversity in coral reef fishes. Folia Parasitologia, 57, 237-262. https://doi.org/10.14411/fp.2010.032

Justine, J.-L., Beveridge, I., Boxshall, G.A., Bray, R.A., Moravec, F. \& Whittington, I.D. (2010b) An annotated list of parasites (Copepoda, Monogenea, Digenea, Cestoda and Nematoda) collected in Emperors and Emperor Bream (Lethrinidae) in New Caledonia further highlights parasite biodiversity estimates on coral reef fish. Zootaxa, 2691, 1-40. https://doi.org/10.11646/zootaxa.2691.1.1
Justine J.-L., Beveridge I., Boxshall G.A., Bray R.A., Miller, T.L., Moravec, F., Trilles, J.-P. \& Whittington, I.D. (2012) An annotated list of fish parasites (Isopoda, Copepoda, Monogenea, Digenea, Cestoda and Nematoda) collected from Snappers and Breams (Lutjanidae, Nemipteridae, Caesionidae) in New Caledonia confirms high parasite biodiversity on coral reef fish. Aquatic Biosystems, 8, 22.

https://doi.org/10.1186/2046-9063-8-22

Khodami, S., Mercado-Salas, N.F., Tang, D. \& Martinez Arbizu, P. (2019) Molecular evidence for the retention of the Thaumatopsyllidae in the order Cyclopoida (Copepoda) and establishment of four suborders and two families within the Cyclopoida. Molecular Phylogeny \& Evolution, 138, 43-52. https://doi.org/10.1016/j.ympev.2019.05.019

Kim, I.-H., Sikorski, A., O'Reilly, M. \& Boxshall, G.A. (2013) Copepods associated with polychaete worms in European seas. Zootaxa, 3651, 1-62.

https://doi.org/10.11646/zootaxa.3651.1.1

Knapp, S. \& Boxshall, G.A. (2010) Biodiversity and Systematics: how have we fared in the International Year of Biodiversity? Systematics \& Biodiversity, 8, 419-422. https://doi.org/10.1080/14772000.2010.543008

Nygren, A., Parapar, J., Pons, J., Meißner, K., Bakken, T., Kongsrud, J.A., Oug, E., Gaeva, D., Sikorski, A., Johansen, R.A., Hutchings, P.A., Lavesque, N. \& Capa, M. (2018) A megacryptic species complex hidden among one of the most common annelids in the North East Atlantic. PLoS ONE, 13(6), e0198356. https://doi.org/10.1371/journal.pone.0198356

Walter, T.C. \& Boxshall, G.A. (2019) World of Copepods database. Accessed from: http://www.marinespecies.org/copepoda (Accessed 15 Oct. 2019) https://doi.org/10.14284/356 